\title{
Influência de citocininas na micropropagação de Mentha x gracilis Sole
}

\author{
GARLET, T.M.B. ${ }^{1 *}$; FLORES, R. ${ }^{2}$; MESSCHMIDT, A.A. ${ }^{3}$ \\ ${ }^{1}$ Universidade de Cruz Alta (UNICRUZ), Centro de Ciências da Saúde (CCS), Laboratório de Cultura de Tecidos, \\ Andrade Neves, 308, CEP: 98025-810, Cruz Alta-Brasil *taneagarlet@hotmail.com²Universidade Federal de \\ Santa Maria (UFSM), Centro de Ciências Naturais e Exatas (CCNE), Laboratório de Biotecnologia Vegetal, Avenida \\ Roraima, 1000, Cidade Universitária, Bairro Camobi, CEP: 97105-900, Santa Maria-Brasil rejane.flores \\ @yahoo.com.br ${ }^{3}$ UNICRUZ, CCS, CEP: 98025-810,Cruz Alta-Brasil alinemesschmidt@yahoo.com.br
}

RESUMO: Menthax gracilis Sole é um híbrido que produz óleos essenciais ricos em monoterpenos. Tendo em vista a propagação clonal desta planta, segmentos nodais provenientes de plantas assépticas, foram cultivados em meio de Murashige e Skoog (MS) suplementado com 0; 0,5; 1,0 e 2,0 $\mu \mathrm{M}$ de cinetina, benzilaminopurina (BAP) ou thidiazuron (TDZ). Após 30 dias, as plantas foram transferidas para meio MS não suplementado com citocinina. Os melhores resultados foram obtidos em meio suplementado com $2 \mu \mathrm{M}$ de TDZ, mostrando ser método viável para a produção rápida de grande número de mudas. Após a transferência das plantas para a casa de vegetação, as plantas propagadas com TDZ apresentam maior número de tricomas glandulares.

Palavras-chave: Lamiaceae, cultivo in vitro, hortelã, tricomas

\begin{abstract}
Cytokinin influence on Mentha x gracilis Sole micropropagation. Mentha $\mathrm{x}$ gracilis Sole is a hybrid that produces essential oils rich in monoterpenes. Aimed at the clonal propagation of this plant, nodal segments from aseptic plants were cultured in Murashige and Skoog (MSO) medium supplemented with $0 ; 0.5 ; 1.0$ and $2.0 \mu \mathrm{M}$ kinetin, benzyl adenine (BAP) or thidiazuron (TDZ). After 30 days, plants were transferred to MOS medium without cytokinin supplementation. The best results were obtained in medium supplemented with $2 \mu \mathrm{M}$ TDZ, which proved to be a viable method for the rapid production of a large number of seedlings. After transference to the greenhouse, plants propagated with TDZ had a larger number of glandular trichomes.
\end{abstract}

Key words: Lamiaceae, in vitro culture, mint, trichomes

\section{INTRODUÇÃO}

O gênero Mentha (Lamiaceae) compreende plantas conhecidas como hortelãs, as quais são muito cultivadas devido à produção de óleos essenciais produzidos por tricomas glandulares presentes nas folhas e caules das plantas. Esses óleos essenciais são usados comercialmente como aromatizantes de alimentos, agentes flavorizantes, em cosméticos, perfumes e medicamentos (Poovaiah et al., 2006).

Mentha x gracilis Sole é um híbrido originado de M. arvensis L. e M. spicata L. (Harley \& Brighton, 1977), que através de uma série de cruzamentos produziu indivíduos estéreis e vários quimiotipos, todos com óleos essenciais ricos em monoterpenos. Recentemente, Garlet et al. (2007) estudaram um quimiotipo de $M$. x gracilis rico em linalol (composição média de $48 \%$ ) e carvona (composição média de 13\%) de grande interesse econômico. O linalol entra na composição de cosméticos, tais como, cremes faciais, loções para o corpo, fragrâncias em creme, desodorantes, perfumes, xampus, produtos de banho, géis, sabonetes e spray para cabelos (Letizia et al., 2003) e em alguns medicamentos. Estudos in vitroe in vivo demonstraram que o linalol exerce atividade antiinflamatória, antinociceptiva, anti-hiperalgésica, anestésica e antioxidante (Peana et al., 2006). A carvona é importante agente antimicrobiano contra bactérias e fungos patogênicos, daí o emprego como composto isolado ou através do óleo, em alimentos e produtos antissépticos. Possui também atividade inseticida, atuando contra moscas das frutas, larvas de insetos, inclusive sobre Aedes aegyptio vetor da dengue hemorrágica (Carvalho \& Fonseca, 2006).

A propagação das hortelãs ocorre preferencialmente por rizomas ou estolões, já que os

Recebido para publicação em 05/05/2009

Aceito para publicação em 12/04/2010

Rev. Bras. PI. Med., Botucatu, v.13, n.1, p.30-34, 2011. 
híbridos, em geral, produzem sementes estéreis pela infertilidade do grão de pólen e têm alto número de ploidia (Wang et al., 2008). Assim, a pureza dos diferentes genótipos de Mentha é mantida por meio da propagação vegetativa (Bhat et al., 2002), o que é importante para manter as características morfológicas e químicas de determinado quimiotipo (Kokkini, 1992).

Devido à necessidade de plantas para estudos químicos e a crescente demanda de matériaprima para a indústria de fitoterápicos, é fundamental o desenvolvimento de técnicas que tenham como propósito a produção de mudas de qualidade de Mentha x gracilis Sole. A micropropagação de plantas medicinais e aromáticas vem sendo difundida devido à possibilidade de produzir grande número de plantas homogêneas e com elevada qualidade fitoquímica, à possibilidade de conservar o germoplasma, garantindo a manutenção do germoplasma existente, além de auxiliar no melhoramento genético (Flores et al., 2006). Inúmeros fatores afetam o cultivo in vitro, sendo os reguladores de crescimento um dos fatores mais importantes quando se trata de plantas medicinais, pois além de alterarem a morfogênese, também influenciam na produção de metabólitos secundários. As citocininas desempenham papel fundamental na produção de plantas in vitro, uma vez que estimulam a indução e proliferação de brotações adventícias (George \& Sherrington, 1984) e, em plantas aromáticas, as citocininas também vêm sendo utilizadas para maximizar a biomassa e a produção de óleos essenciais (Stoeva \& lliev, 1997).

A propagação clonal in vitro de Mentha $x$ gracilis Sole abre perspectivas para a produção de mudas uniformes e de alta qualidade fitoquímica e sanitária, as quais poderão ser fontes de matériaprima para a indústria farmacêutica. Desta forma, este trabalho teve como objetivo avaliar as concentrações de citocininas na micropropagação de Mentha x gracilis Sole a partir de segmentos nodais.

\section{MATERIAL E MÉTODO}

O trabalho foi conduzido no Laboratório de Cultura de Tecidos Vegetais da Universidade de Cruz Alta (UNICRUZ), Cruz Alta, RS. Plantas jovens de Mentha $x$ gracilis Sole cultivadas no Jardim de Plantas Medicinais da UNICRUZ, foram transplantadas para recipientes contendo solo e mantidas em casa de vegetação do Laboratório de Multiplicação Vegetal da UNICRUZ. Exsicata da espécie encontra-se depositada no Herbário da UNICRUZ, sob no 1078, com a determinação feita pelo Dr. Ray Harley do Royal Botanic Gardens, Kew, Inglaterra. Segmentos caulinares jovens, com 30 dias de idade, de $M . x$ gracilis foram desinfestados, conforme metodologia proposta por Flores et al. (2006).
Posteriormente, segmentos nodais $(1 \mathrm{~cm})$ foram inoculados e cultivados em tubos de ensaio ( $25 \times 150 \mathrm{~mm}$ ), contendo $10 \mathrm{~mL}$ do meio nutritivo MS (Murashige \& Skoog, 1962), acrescido de $30 \mathrm{~g} \mathrm{~L}^{-1} \mathrm{de}$ sacarose, $7 \mathrm{~g} \mathrm{~L}^{-1}$ de ágar e suplementado com concentrações $(0,5 ; 1,0$ e $2,0 \mu \mathrm{M})$ de 6 benzilaminopurina (BAP), cinetina e thidiazuron (TDZ). $\mathrm{O} \mathrm{pH}$ foi ajustado para 5,8 e o meio foi autoclavado (1 atm, $120^{\circ} \mathrm{C}$ ) durante 20 minutos. Os explantes foram mantidos em sala de crescimento com temperatura de $25 \pm 2^{\circ} \mathrm{C}$, fotoperíodo de 16 horas de luz e intensidade luminosa de $40 \mu \mathrm{mol} \mathrm{m}^{-2} \mathrm{~s}^{-1}$.

Visando a favorecer 0 alongamento e 0 enraizamento, após trinta dias de cultivo, nas diferentes concentrações de citocininas, os segmentos nodais dos brotos regenerados foram seccionados e transferidos para frascos de cultivo contendo $30 \mathrm{~mL}$ de meio MS não suplementado com citocininas.

O material foi avaliado aos 30 dias após cada inoculação, por meio do número médio de brotos, número médio de segmentos nodais, comprimento dos brotos $(\mathrm{cm})$, número de folhas, porcentagem de enraizamento e número de raízes.

Para a aclimatização, microplantas completas (com partes aéreas e raízes desenvolvidas) e com 30 dias de idade foram transferidas para sacos plásticos $\left(1000 \mathrm{~cm}^{3}\right)$, contendo $500 \mathrm{~cm}^{3}$ de substrato comercial Plantmax Hortaliças e mantidas em casa de vegetação sob condições de luminosidade parcial, temperatura e fotoperíodo naturais. A umidade do substrato foi mantida entre 45 e $60 \%$ da capacidade de campo, através de irrigações frequentes. Cada recipiente de cultivo foi coberto com plástico transparente. Sete dias após o plantio, a cobertura de plástico começou a ser retirada gradativamente. Após 15 dias do plantio, a cobertura foi retirada por completo, mantendo-se a umidade das folhas por meio de aspersão. Aos 30 dias da transferência das plantas para o substrato, foram feitas avaliações da percentagem de sobrevivência, do número médio de brotos, comprimento da planta $(\mathrm{cm})$ e número médio de folhas.

O delineamento experimental utilizado nos ensaios de cultivo in vitro foi o inteiramente casualizado. Utilizaram-se cinco repetições, sendo cada repetição formada por cinco plantas. Os dados foram submetidos à análise de variância pelo teste de Tukey, ao nível de $1 \%$ de probabilidade de erro.

Após 240 dias do plantio, as plantas foram avaliadas em relação à densidade de tricomas glandulares da epiderme adaxial. Folhas do $4^{\circ}$ nó superior foram retiradas para confecção de lâminas pelo método de moldes (Prado \& Casali, 2006), aplicando-se esmalte incolor como molde. A 
observação dos tricomas glandulares foi realizada utilizando-se microscópio óptico (aumento de 100x). Foram confeccionadas seis lâminas (repetições) por tratamento, sendo escolhidos ao acaso, 10 campos de observação para cada lâmina. Os resultados foram expressos em número médio de tricomas glandulares por $\mathrm{cm}^{2}$ de área foliar.

\section{RESULTADO E DISCUSSÃO}

Todos os tratamentos apresentaram 100\% de regeneração com desenvolvimento de brotações axilares. Aos 30 dias de cultivo in vitro, verificou-se maior número médio de brotações, segmentos nodais e folhas por explante no meio de cultura suplementado com $2 \mu \mathrm{M}$ de TDZ (Tabela 1). O TDZ é uma difeniluréia com atividade de citocinina que estimula a proliferação em muitas espécies de plantas lenhosas (Huetteman \& Preece, 1993) e também entre membros da família Lamiaceae, como o gênero Mentha. Visando a produção de brotações adventícias em entrenós de Mentha $\mathrm{x}$ gracilis Sole, Poovaiah et al. (2006) obtiveram melhores resultados em meio contendo 4,5 $\mu \mathrm{M}$ de TDZ. Do mesmo modo, Wang et al. (2008) registraram $100 \%$ de regeneração de brotações em entrenós de Mentha x piperita L., utilizando meios suplementados com 2,27 a 9,08 $\mu \mathrm{M}$ de TDZ.

Observou-se uma redução no alongamento das brotações nas concentrações mais elevadas (1 e $2 \mu \mathrm{M}$ ) de BAP e TDZ (Tabela 1). Brotações mais alongadas foram registradas em meio suplementado com 1 e $2 \mu \mathrm{M}$ de cinetina, as quais apresentaram comprimento médio de 4,3 e $4,0 \mathrm{~cm}$, respectivamente (Tabela 1). Resultados semelhantes foram observados durante a proliferação in vitro de Salvia nemorosa L., onde houve redução no alongamento das plantas com o aumento da concentração de BAP ou TDZ (Skala \& Wysokinska, 2004). Da mesma forma, Poovaiah et al. (2006) verificaram que concentrações superiores a 2,3 $\mu \mathrm{M}$ de TDZ inibiram o alongamento dos brotos de Menthax gracilis, o que corroboram os resultados obtidos no presente estudo.

As plantas apresentaram maior percentagem de enraizamento quando cultivadas em meio isento de reguladores de crescimento, bem como nos meios acrescidos de cinetina e naqueles contendo a menor concentração de BAP ou TDZ (Tabela 1). Assim, os resultados demonstram que as concentrações de cinetina utilizadas não afetaram o enraizamento das plantas, por outro lado, concentrações superiores a $0,5 \mu \mathrm{M}$ de BAP e TDZ, reduziram ou inibiram a regeneração de raízes, respectivamente (Tabela 1).

A formação de plantas completas em meio de regeneração contendo $2 \mu \mathrm{M}$ de cinetina mostrou resultado interessante para a propagação rápida de M. $x$ gracilis, visto que as plantas apresentaram partes aéreas e raízes bem desenvolvidas em curto espaço de tempo, dispensando as etapas de alongamento e enraizamento.

Após a transferência dos brotos, inicialmente cultivados em meio contendo as diferentes citocininas, para um meio isento de fitorreguladores, constatouse que os explantes oriundos do meio suplementado com $2 \mu \mathrm{M}$ de cinetina apresentaram os melhores resultados em todos os parâmetros analisados (Tabela 2).

É importante que durante a fase de enraizamento os brotos continuem a crescer, pois

TABELA 1. Morfogênese em segmentos nodais de Mentha $x$ gracilis Sole, cultivados em meio MS suplementado com concentrações de cinetina, BAP e TDZ, durante 30 dias.

\begin{tabular}{ccccccc}
\hline & $\mu \mathrm{M}$ & $\begin{array}{c}\text { Número de } \\
\text { brotos }^{*}\end{array}$ & $\begin{array}{c}\text { Número de } \\
\text { segmentos nodais }\end{array}$ & $\begin{array}{c}\text { Comprimento dos } \\
\text { brotos }(\mathrm{cm})^{*}\end{array}$ & $\begin{array}{c}\text { Número } \\
\text { de folhas }^{*}\end{array}$ & $\begin{array}{c}\text { Enraizamento } \\
(\%)^{*}\end{array}$ \\
\hline- & 0 & $2,0 \mathrm{c}$ & $9,2 \mathrm{bcde}$ & $2,3 \mathrm{bc}$ & $17,0 \mathrm{bc}$ & $100 \mathrm{a}$ \\
\hline \multirow{3}{*}{ CINETINA } & 0,5 & $2,0 \mathrm{c}$ & $10,6 \mathrm{bc}$ & $3,4 \mathrm{ab}$ & $17,3 \mathrm{bc}$ & $100 \mathrm{a}$ \\
& 1,0 & $2,4 \mathrm{c}$ & $11,2 \mathrm{~b}$ & $4,3 \mathrm{a}$ & $19,1 \mathrm{~b}$ & $100 \mathrm{a}$ \\
& 2,0 & $3,0 \mathrm{bc}$ & $11,0 \mathrm{bc}$ & $4,0 \mathrm{a}$ & $19,5 \mathrm{~b}$ & $96 \mathrm{a}$ \\
\hline \multirow{3}{*}{$\mathrm{BAP}$} & 0,5 & $2,7 \mathrm{bc}$ & $9,5 \mathrm{bcd}$ & $2,2 \mathrm{bc}$ & $17,0 \mathrm{bc}$ & $96 \mathrm{a}$ \\
& 1,0 & $2,6 \mathrm{bc}$ & 6,7 ef & $1,9 \mathrm{c}$ & $11,3 \mathrm{~cd}$ & $32 \mathrm{bc}$ \\
& 2,0 & $2,7 \mathrm{bc}$ & $6,8 \mathrm{def}$ & $1,7 \mathrm{c}$ & $10,0 \mathrm{~d}$ & $60 \mathrm{ab}$ \\
\hline \multirow{3}{*}{ TDZ } & 0,5 & $2,0 \mathrm{c}$ & $6,0 \mathrm{f}$ & $2,6 \mathrm{bc}$ & $10,8 \mathrm{~cd}$ & $100 \mathrm{a}$ \\
& 1,0 & $4,2 \mathrm{~b}$ & $8,4 \mathrm{cdef}$ & $1,5 \mathrm{c}$ & $17,4 \mathrm{bc}$ & $0 \mathrm{c}$ \\
& 2,0 & $14,1 \mathrm{a}$ & $19,1 \mathrm{a}$ & $1,5 \mathrm{c}$ & $31,8 \mathrm{a}$ & $0 \mathrm{c}$ \\
\hline
\end{tabular}

*Médias seguidas de mesma letra nas colunas não diferem entre si pelo Teste de Tukey em nível de 1\% de probabilidade. 
Skala \& Wysokinska (2004) comentam que, em muitas espécies, plantas maiores sobrevivem melhor ao transplante e aclimatização que plantas menores. No presente estudo, as plantas apresentaram 100\% de sobrevivência durante a fase de aclimatização, independente do meio de cultivo utilizado na fase de multiplicação. Após 30 dias do plantio, as plantas apresentaram uma média de 2,2 brotações, 29,7 folhas por planta e comprimento médio de $12,7 \mathrm{~cm}$, não sendo observada diferença estatística significativa entre os tratamentos.

Após 240 dias da aclimatização, as plantas foram avaliadas em relação à presença de tricomas glandulares. As plantas propagadas em meio de cultura suplementado com TDZ, principalmente nas concentrações 1,0 e $2,0 \mu \mathrm{M}$, foram as que apresentaram maior número de tricomas, seguido pelo BAP e cinetina (Tabela 3).

As citocininas induzem vários efeitos fisiológicos nas plantas. Em espécies aromáticas, as citocininas derivadas das feniluréias mostraram favorecer a biomassa e a produção de óleos essenciais em hortelã (Stoeva \& lliev, 1997). Em Salvia fruticosa Mill., Arikat et al. (2004) constataram que o incremento na produção de óleos essenciais em plantas aromáticas cultivadas in vitro pode estar associado ao efeito das citocininas adicionadas ao meio. No presente estudo, os resultados mostraram

TABELA2. Morfogênese em segmentos nodais de plantas de Menthax gracilis Sole, inicialmente regeneradas em meio MS com concentrações de cinetina, BAP ou TDZ e subcultivados em meio MS não suplementado com citocininas, aos 30 dias de idade.

\begin{tabular}{|c|c|c|c|c|c|c|c|}
\hline & $\mu \mathrm{M}$ & $\begin{array}{l}\text { Número de } \\
\text { brotos* }^{*}\end{array}$ & $\begin{array}{l}\text { Número de } \\
\text { segmentos nodais* }\end{array}$ & $\begin{array}{c}\text { Comprimento } \\
\text { dos brotos }(\mathrm{cm})^{*}\end{array}$ & $\begin{array}{l}\text { Número de } \\
\text { folhas* }\end{array}$ & $\begin{array}{c}\text { En raizamento } \\
(\%)^{*}\end{array}$ & $\begin{array}{l}\text { Núumero } \\
\text { de raízes * }\end{array}$ \\
\hline- & 0 & $1,2 \mathrm{bc}$ & $4,4 \mathrm{~cd}$ & $2,6 b c$ & $8,9 b c$ & $74,7 \mathrm{ab}$ & $3,3 a b c$ \\
\hline \multirow{3}{*}{ CINETINA } & 0,5 & $1,9 a b$ & $8,2 a b$ & $5,0 a$ & $15,9 a b$ & $92,0 \mathrm{a}$ & $4,7 a b$ \\
\hline & 1,0 & $1,8 \mathrm{ab}$ & $8,0 \mathrm{ab}$ & $4,0 a b$ & $15,7 a b$ & 90,7 a & $5,1 a b$ \\
\hline & 2,0 & $2,0 \mathrm{a}$ & $9,2 \mathrm{a}$ & $4,9 a$ & $18,6 a$ & $98,7 \mathrm{a}$ & $5,3 a$ \\
\hline \multirow{3}{*}{ BAP } & 0,5 & $1,8 a b$ & $7,8 \mathrm{abc}$ & $3,7 a b$ & $15,1 \mathrm{abc}$ & $88,0 \mathrm{a}$ & $3,9 a b c$ \\
\hline & 1,0 & $1,7 a b$ & $7,6 \mathrm{abc}$ & $2,8 \mathrm{bc}$ & $15,6 a b$ & $92,0 \mathrm{a}$ & $3,9 a b c$ \\
\hline & 2,0 & $0,8 c$ & $3,1 \mathrm{~d}$ & $1,5 c$ & $a a_{c}$ & $48,0 \mathrm{~b}$ & $1,8 \mathrm{c}$ \\
\hline \multirow{3}{*}{ TDZ } & 0,5 & $1,4 a b c$ & $4,9 \mathrm{bcd}$ & $2,4 \mathrm{bc}$ & $10,6 \mathrm{abc}$ & $73,3 \mathrm{ab}$ & $3,1 \mathrm{bc}$ \\
\hline & 1,0 & $1,4 a b c$ & $6 \mathrm{bcd}$ & $2,9 \mathrm{bc}$ & $11,6 a b c$ & $86,7 \mathrm{a}$ & $3,9 a b c$ \\
\hline & 2,0 & $1,6 a b$ & $7,5 \mathrm{abc}$ & $4,0 \mathrm{ab}$ & $13,1 \mathrm{abc}$ & $72,0 \mathrm{ab}$ & $4,0 \mathrm{ab}$ \\
\hline
\end{tabular}

*Médias seguidas de mesma letra nas colunas não diferem entre si pelo Teste de Tukey em nível de 1\% de probabilidade.

TABELA 3. Número médio de tricomas glandulares em folhas de Mentha x gracilis Sole, propagadas in vitro com em meio contendo citocininas, após 240 dias da transferência das plantas para o substrato.

\begin{tabular}{ccc}
\hline & $\mu \mathrm{M}$ & $\begin{array}{c}\text { Número médio de tricomas glandulares } \\
\text { por } \mathbf{c m}^{2} \text { de área foliar* }\end{array}$ \\
\hline- & 0 & $248 \mathrm{~cd}$ \\
\hline \multirow{3}{*}{ CINETINA } & 0,5 & $220 \mathrm{~d}$ \\
& 1,0 & $291 \mathrm{bcd}$ \\
& 2,0 & $295 \mathrm{bcd}$ \\
\hline \multirow{3}{*}{ BAP } & 0,5 & $339 \mathrm{abc}$ \\
& 1,0 & $366 \mathrm{ab}$ \\
& 2,0 & $335 \mathrm{abc}$ \\
\hline \multirow{2}{*}{ TDZ } & 0,5 & $374 \mathrm{ab}$ \\
& 1,0 & $437 \mathrm{a}$ \\
& 2,0 & $433 \mathrm{a}$ \\
\hline
\end{tabular}

*Médias seguidas de mesma letra nas colunas não diferem entre si pelo Teste de Tukey em nível de 5\% de probabilidade. 
que a adição do TDZ ao meio de cultura incrementou a produção de tricomas glandulares nas folhas das plantas, porém a análise química será necessária para verificar se as plantas micropropagadas com essa citocinina apresentam maior produção de óleos essenciais.

Os resultados obtidos neste estudo permitiram concluir que o cultivo dos segmentos nodais de Mentha x gracilis em meio MS suplementado com $2 \mu \mathrm{M}$ de TDZ é uma metodologia viável para a produção rápida de grande número de mudas. Após a transferência das plantas para a casa de vegetação, as plantas propagadas com TDZ apresentam maior número de tricomas glandulares.

\section{AGRADECIMENTO}

À Fundação de Amparo à Pesquisa do Estado do Rio Grande do Sul (FAPERGS) pela bolsa de iniciação científica do 3 autor.

\section{REFERÊNCIA}

ARIKAT, N.A. et al. Micropropagation and accumulation of essencial oils in wild sage (Salvia fruticosa Mill.). Scientia Horticulturae, v.100, p.193-202, 2004.

BHAT, S. et al. Mentha species: In vitro regeneration and genetic transformation. Molecular Biology Today, v.3, n.1, p.11-23, 2002.

CARVALHO, C.C.R.; FONSECA, M.M.R. Carvone: why and how should one bother to produce this terpene. Food Chemistry, v.95, p.413-22, 2006.

FLORES, R.; MALDANER, J.; NICOLOSO, F.T. Otimização da micropropagação de Pfaffia tuberosa (Spreng.) Hicken. Ciência Rural, v.36, n.3, p.845-51, 2006.

GARLET, T.M.B. et al. Produção e qualidade do óleo essencial de menta em hidroponia com doses de potássio. Ciência Rural, v.37, n.4, p.956-62, 2007.
GEORGE, E.F.; SHERRINGTON, N.P.D. Plant propagation by tissue culture. Eversley: Exegetics Limited, 1984. 593p.

HARLEY, R.M.; BRIGHTON, C.A. Chromosome numbers in the genus Mentha. Botanical Journal of the Linnean Society, v.74, p.71-96, 1977.

HUETTEMAN, C.A.; PREECE, J.E. Thidiazuron: a potent cytokinin for woody plant tissue culture. Plant Cell, Tissue and Organ Culture, v.33, n.2, p.105-19, 1993.

KOKKINI, S. Essential oils as taxonomic markers in Mentha. In: HARLEY, R.M.; REYNOLDS, T. (Eds.). Advances in Labiatae Science. Kew: Royal Botanic Gardens, 1992. p.325-34.

LETIZIA C.S. et al. Fragrance material review on linalol. Food and Chemical Toxicology, v.41, p.943-64, 2003. MURASHIGE, T.; SKOOG, F. A revised medium for rapid growth and bioassays with tabacco tissue cultures. Physiologia Plantarum, v.15, p.473-97, 1962.

PEANA, A.T. et al. (-)- Linalool inhibits in vitro NO formation: Probable involvement in the antinociceptive activity of this monoterpene compound. Life Science, v.78, p.719-23, 2006.

POOVAIAH, C.R.; WELLER, S.C.; JENKS, M.A. Adventitious shoot regeneration of scotch spearmint (Mentha x gracilis Sole) in vitro. In Vitro Cellular \& Developmental Biology-Plant, v.42, p.354-8, 2006 PRADO, C.H.B.A.; CASALI, C.A. Fisiologia vegetal: práticas em relações hídricas, fotossíntese e nutrição mineral. Barueri: Manole, 2006. 448p.

SKALA, E.; WYSOKINSKA, H. In vitro regeneration of Salvia nemorosa L., from shoot tips and leaf explants. In Vitro Cellular \& Developmental Biology - Plant, v.40, p.596692, 2004.

STOEVA, T.; ILIEV, I. Influence of some phenylurea cytokinins on spearmint essential oil composition. Bulgarian Journal Plant Physiology, v.23, n.3-4, p.66-71, 1997.

WANG, X. et al. Highly efficient in vitro adventitious shoot regeneration of peppermint (Mentha $x$ piperita L.) using internodal explantes. In Vitro Cellular \& Developmental Biology - Plant, on line first, 21 November, 2008. Disponível em: <http://www.springerlink.com/content/ b458513100116546>. Acesso em: 15 abr. 2009. 